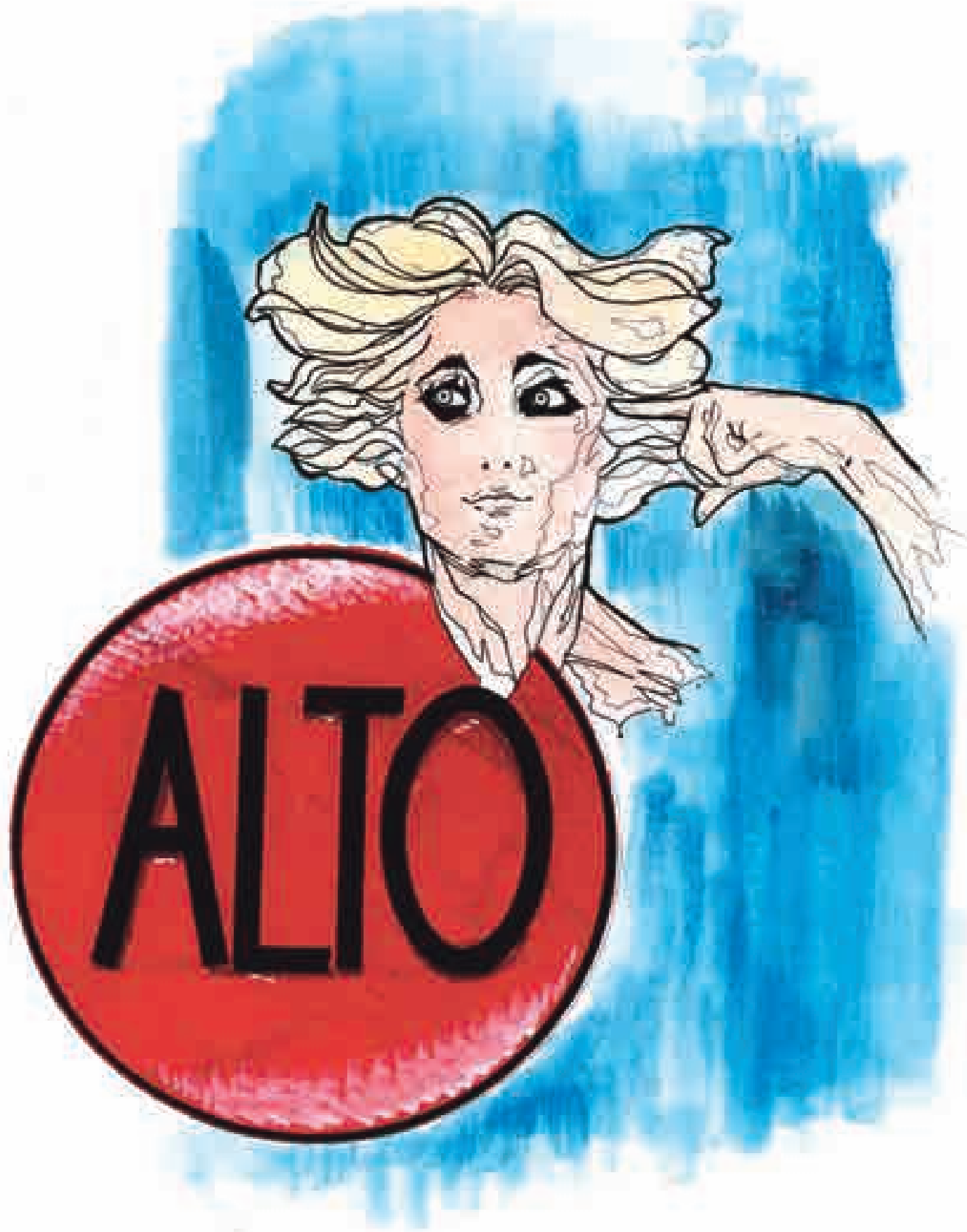

Ilustración 21. Antanas Mockus hizo su aparición en el "Santoto", a las 2:00 p.m., un sinnúmero de asistentes se abalanzaron sobre él, le hicieron preguntas, comentarios y se tomaron fotos. 



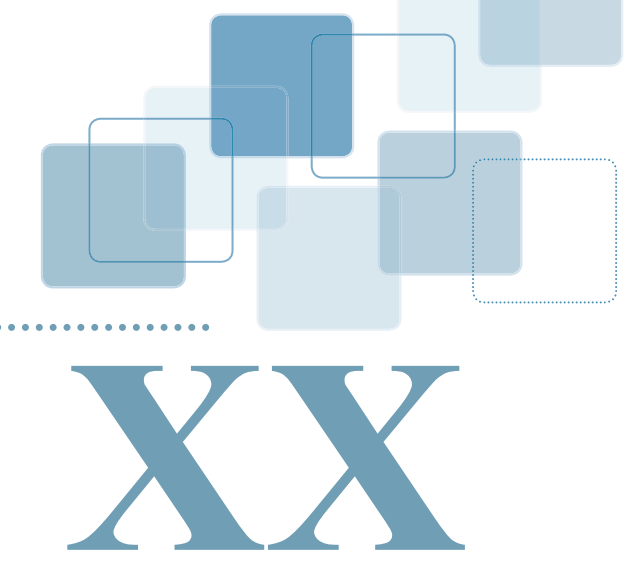

\section{AQUÍ ACABA LA ACCIÓN \\ PERO NO EL SENTIDO}

Un grupo folklórico engalanó el almuerzo. La tarde cálida y la expectativa generada por los conferencistas Fabián Sanabria y Andrés Argüello caracterizaron la jornada de la mañana. Antanas Mockus hizo su aparición en el "Santoto", a las 2:00 p.m., un sinnúmero de asistentes se abalanzaron sobre él, le hicieron preguntas, comentarios y se tomaron fotos. Minutos después, Antanas, dijo lo siguiente:

De algún modo, todos los que estamos aquí estamos familiarizados con los diseños, con los cuales al hablar, sin embargo, la esperanza, es mostrarlos o ahondarlos un poco distinto. Si en este momento fuera rector de un colegio a la entrada escribiría: aqi se aplaza la acción y en letra más pequeñita: pero no el sentido. El sistema educativo saca a la gente de la vida productiva, le pide a la gente que suspenda una serie de prácticas que en la sociedad se dan y que asuma otras prácticas que se dan en el sistema escolar. La finalidad es preparar a la gente para la acción, pero el método es sacar a la gente del flujo de la acción.

La mayor parte de la acción humana es muy ordinaria: oficios, profesiones y tareas cotidianas pueden implicar básicamente repetición de comportamientos. El $q$ bb, q́ hy puede significar comportamientos que operan de manera bastante rutinaria. Todos los que estamos aquí hemos sido contagiados de una extraña enfermedad que llamamos 
"tradición académica", si se tuviera la suficiente información se retrasaría la serie de contactos que nos lleva, por lo menos hasta Sócrates, somos herederos de él. La tradición académica es como el sida: todos se adquiere por contacto directo, pero a diferencia del sida, el contacto tiene que ser prolongado.

Voy a caracterizar "la tradición académica", esto es muy esquemático, en la realidad tiene muchas más complejidades, pero básicamente hay tradición académica porque hay discusión racional. Toda cultura humana tiene la posibilidad de discutir racionalmente ¿cómo opera eso? Cada vez que hablamos pretendemos que lo que decimos se puede entender, pretendemos que lo que decimos o lo que suponemos que decimos o lo que suponemos en la acción que estamos, por ejemplo, pidiendo... si yo le digo a alguien: să gase del salón, pues estoy suponiendo que está en el salón. Cada vez que hablamos pretendemos que lo que decimos puede ser comprendido, que es verdad, que revela sinceramente mis sentimientos. Si digo que estoy contento de estar acá se da una pretensión de sinceridad, que es la pretensión también de ser justo, de ser correcto, de actuar bien, de acuerdo con las normas que compartimos.

Ahora, la maravilla es que cualquier ser humano puede desear "entender otro día", entonces se abren dos caminos: Si estamos de buenas, $b$ en, chr lamos, pero si estamos de malas, cho o no entiendo, me voy. Se puede romper la comunicación o puede suceder una maravilla que es no entiendo, pero explíqe me, deme un ejemplo, dígamelo de otra manera, dígamelo en otro idioma, dígamelo con las manos. Entonces en ese romperse la comunicación, la pretensión de validez, sea de la que algo es comprensible, de la que algo es verdadero o cualquiera de las otras dos que voy a comentar. La pretensión puede ser cuestionada pero sin que se rompa la comunicación, no puede decírsele al otro usted no es sincero, dijo qe estab contento y yo lo vi entrando con la cara triste. Usted puede, a raíz de esa concertación, romper la comunicación, yo puedo romperla o puedo decirle: déjeme yo le explico porqe tenía la cara arrugada al entrar o lo qe vio fue las he llas porqe acab de estar donde el odontólogo. No estoy triste pero tengo una mejilla todavía h nchda por la anestesia. Si yo le dije a alguien salgase del salón, él me puede decir usted con qé derech me saca del salón. Podemos entablar 
una discusión donde intercambiamos argumentos y, al final, podemos estar de acuerdo en lo que usted dijo o en lo que yo dije o pretendí o en una tercera cosa, que emerge de la comunicación. Entonces, la discusión racional que existe en toda cultura humana tiene un poder impresionante para no solo generar comunicación y, para entroncar la comunicación con el mundo de lo justo, con el mundo de lo sincero, con el mundo de la verdad y con el mundo de la inteligibilidad.

Miles y miles de años después de que esta posibilidad de impugnar pretensiones de validez en la conversación se empezara a cultivar, llegamos a cosas como ciencias del lenguaje, como ciencias del mundo objetivo, como ciencias del mundo interno y ciencias de la normatividad que van desde el derecho hasta la ética personal, pasando por el estudio y las normas sociales. Entonces, en toda cultura pueden surgir pretensiones de validez, cualquier conversación involucra pretensiones de validez. Si yo empezara a hablar en lituano algo sucedería, ya que alguien levantaría la mano y diría: no entendemos lo qe nos está diciendo. Y de nuevo, la comunicación se puede romper o puede proseguir cambiando de idioma, buscando un idioma común, etc. Entonces el diálogo cuestionador, el diálogo que se atreve a decirle al otro: tal vez lo qe usted dice con tanta convicción no es cierto, es un instrumento básico de la tradición académica. Entonces, si esa fuera la única característica diríamos que en toda cultura hay tradición académica.

En toda cultura hay algo parecido a la tradición académica, pero hay métodos diferenciadores. Tal vez el más grande sea la escritura, sin escritura la discusión es, de algún modo, un poco imprecisa o puede ser muy precisa pero cuando se va a recordar varios días después uno puede omitir algunos detalles. Muchas veces en una discusión verbal uno, sin mala fe, ajusta un poquitico su posición para volverla más defendible. Entonces, sin la escritura la discusión tendría limitaciones, sin escritura la persuasión tiende a basarse un poco en retórica. Yo puedo observar muchas mujeres en el auditorio, puedo celebrar los avances de la mujer en relación a una misma tradición que durante mucho tiempo ha clasificado fuertemente a la humanidad por género - no quiero meterme en el lío de defender el sacerdocio femenino o cosas de ese estilo-, pero puedo decir que es una maravilla que una institución como esta 
las mujeres se hayan abierto el espacio en el terreno enorme que hay o puedo, mirando los estudiantes, decirles: iqé maravilla qe estudian en un colegio masculino!

Discutir sin escribir es distinto que discutir escribiendo. Cuando se escribe hay una posibilidad de crítica enorme frente lo que uno plantea, o sea, uno escribe y después se devuelve a veces dos o tres días más tarde, y el mismo texto lo puede ver como producido por otra persona. Ya dije que el texto reduce las tentaciones retóricas, también los textos traen retórica, pero es distinta la lógica de la retórica. La lógica es como la retórica cuando el público es universal, cuando el público no es el aquí y el de ahora, el de este salón. Aprovechando cualidades que ustedes tienen, yo podría persuadirlos de algunas cosas, pero cuando escribo no sé quién me va a leer, no sé en cuanto tiempo me va a leer y mi escritura puede tender a ser universal. Entonces, la tradición académica trata de producir textos de validez, de vigencia geográficamente universal y de vigencia histórica o temporal grande.

También sabemos que muchos de nuestros textos son efímeros, pero Galileo, por ejemplo, que no era nada modesto decía: ¡qué maravilla esta invención del alfabeto, me permití hablar de tú a tú con Aristóteles, con Platón, pero también con los que vendrán! Entonces un Galileo se sabía importar.

Lo otro era la implementación gráfica. Ahí la deuda de la universidad con la tradición católica es enorme. El catolicismo tuvo la apuesta absolutamente magistral de autorizar imágenes y decirle a la gente: no confundan las imǵe nes con lo qe la imagen intenta representar. Entonces en las juntas directivas de las grandes compañías, en cantidad espacios académicos la sesión de trabajo comienza diciendo: esto qe presento es una caricatura, es una simplificación, la realidad es mucho má compleja, pero un buen terreno más adelante estamos metidos por qué esta flechita va para allá y también para allá. La fuerza de la representación gráfica es enorme. Entonces, tenemos escritura, representación gráfica, representación geométrica, algebraica y eso va potenciando mucho la discusión racional. Se escribe para discutir, se lee para discutir, se discute para escribir, se discute para escoger qué se va a leer. 
Hay perfeccionamiento en la vida cotidiana, en la vida práctica. Los filósofos, tal vez no todos, querían ser mejores en la vida y utilizaban la discusión racional: la lectura, la escritura como elementos para buscar ese mejor vivir. El cristianismo retomó parte de sus elementos, aprendió muchas escuelas socráticas llamadas por algunos menores, por ejemplo, los estoicos. Entonces, de esto estamos contagiados irremediablemente y esto es parte de lo que nuestros alumnos aprenden cuando estudian con nosotros. Tal vez, falta describir cómo funciona esto hoy en día. Estas maravillas antes de ser en la realidad fueron sobre el plano, son diseñadas, fueron discutidas en comités, equipos de trabajo, a veces, hasta el último detalle, o sea este no es un producto artesanal, esto no es un trabajador sacando una flauta de un palo de bambú.

Quiero hablarles del aplazamiento de la acción en este contexto ¿por qué se aplaza la acción? Para tener una relación con ella más tensa, más compleja donde lo que voy a hacer está muy influido por lo que sabemos. Recientemente no hay tantas películas sobre científicos locos como las que veía yo de niño, pero me impactaba mucho...Muchas veces se omitía esto, se omitía esto y estaba el científico solo haciendo muestras como Melquiades de Cien Ã̃s de $\delta l$ edad. Una de las soledades que se revela es la del famoso, a veces, está buscando la piedra filosofal, la manera de convertir los otros metales en oro, a veces llama a José Arcadio y trabajan juntos, pero típicamente el académico no es representado como parte de una comunidad y no suele verse su trabajo como un trabajo colectivo. Pero eso es un poco como la historia de las religiones. En la Iglesia Católica tenemos santos individualizados, aunque el ideal de vida santa sea universal, sea deseable que prácticamente todo el mundo sea santo.

Este es en resumen, lo que quiero trabajar: pedagogía y ciudadanía, pedagogía y hedonismo, pedagogía como reconstrucción de mecanismos muy sutiles, por los cuales se reproducen como roles, identidades. Todos ya sabemos que vestir a los muchachitos y a las muchachitas de rosado y darles juguetes de armar y muñecas a las muchachitas, pues eso reproduce una cantidad de género, pues algo parecido vivimos así en la clase. Cuando el curso es mixto, en matemáticas, en el año 70 se hacen estudios muy precisos de a quien miró el profesor en clase y 
en clase de matemáticas el profesor de matemáticas de los años 70 , en Estados Unidos, miraba más a los hombres que las mujeres. Estoy dando ejemplos marginales de cómo el sistema educativo, de algún modo, nos ayuda a encontrar una identidad a través de qué nos enseña, qué espera de nosotros, qué logramos satisfacer de lo que el sistema educativo espera.

Esta es una aproximación crítica. Uno de mis primeros artículos sobre estos temas se llamó: "Las funciones implícitas del sistema educativo", era un poco atrevido. Decíamos: cuando usted enseña matemáticas también enseña moral, también manda mensajes sobre lo que es correcto y sobre lo que no es correcto o enseña a manejar el tablero. Muchos de los profesores de matemáticas solo aprendieron a manejar el tablero viendo a profesores que manejaban bien el tablero. La tesis que quiero sostener es que aquí se aplaza la acción, la acción es una fuente de sentido, muchas veces uno se imagina que podría enseñar mejor si tuviera un componente más grande de acción, que uno a los alumnos de 4 a 5 años, hacemos la teoría del proceso $\mathrm{x}-\mathrm{y}$ y a las seis de la mañana llegamos con las herramientas y construimos lo que tengamos que construir. La paradoja de la enseñanza, es que uno a veces pre-visiona el elemento discusión racional por abreviar el tiempo para atraer al estudiante a lo que se sabe hoy en día. Hay muchas cosas que se discutieron siglos y que hoy en día enseñamos en una hora o dos horas. Uno tiene que volver a recorrer un camino grande, que haya una selección fuerte de contenidos.

Cuando se aplaza la acción y se cultiva el sentido hay una tensión grande entre reproducir, según la manera, llevar al joven a donde vamos supuestamente nosotros, una misma tendencia a cambiar las cosas tenemos una regresión ambivalente muy fuerte con la tradición. Es decir, somos portadores de una tradición, así como la de Sócrates y al mismo tiempo somos herederos de muchos seres humanos que fueron rebeldes. El mismo Sócrates se vio atrapado en un dilema horrible que era o desobedecer a la Ley o desobedecer a su conciencia. Entonces, él se toma la cicuta que es una figura trágica, pues muestra que a veces no podemos satisfacer al mismo tiempo su conciencia y la ley de su sociedad, pero Sócrates no hace lo que harán los cínicos que era poner 
la moral por encima de la cultura. Habrán oído chistes de los cínicos: se vestía alguno con un tonel, se metían a los templos a hacer orgias, cuando venía un poderoso le decía: qi tese de ah qe me tapa el sol; se declaraban ciudadanos del mundo, se creían superiores por su cultivo de la moral a cualquier tradición específica, comían crudo que en términos antropológicos y medicinales es todo un lío.

Entonces, la práctica educativa involucra muchos elementos de tradición y muchos de ruptura y transformación. Ambas tareas requieren mucha preparación y mucho esfuerzo. Alguien decía de Picasso que había llegado a pintar un bigote con un par b ochz os, pero antes, en su formación académica, lo pintó pelo por pelo. Lo primero es esa tensión, lo segundo hay corresponsabilidad entre padres, educadores, Estado, comunidad, sociedad. Algo que es obvio, uno puede estudiar cursos en clase sobre ciudadanía, pero donde más ciudadanía aprende cuando tiene la oportunidad de tratar a la otra persona como un ciudadano o reclamar o conseguir amistosamente que el otro lo trate como un ciudadano.

Una cascada de aplausos apareció tras el final de la intervención de Antanas Mockus. El hombre respondió algunas preguntas de los asistentes, se tomó fotografías y abandonó el colegio. El cierre del evento estuvo a cargo de fray Carlos Mario Alzate, O.P., rector de la Universidad Santo Tomás, por último, los asistentes recibieron el certificado de asistencia y se marcharon del "Santoto". 
